\title{
Recycled Aggregate Concrete including Various Contents of Metakaolin: Mechanical Behavior
}

\author{
Khaleel H. Younis $\mathbb{D}^{1,2}$ Abdulfattah A. Amin, ${ }^{1}$ Hemin G. Ahmed, ${ }^{3}$ and \\ Shelan M. Maruf $\mathbb{D D}^{1}$ \\ ${ }^{1}$ Department of Road Construction, Erbil Technology Institute, Erbil Polytechnic University, Erbil, Iraq \\ ${ }^{2}$ Civil Engineering Dept., Tishk International University, Erbil, Iraq \\ ${ }^{3}$ Surveying Dept., Erbil Technology Institute, Erbil Polytechnic University, Erbil, Iraq \\ Correspondence should be addressed to Khaleel H. Younis; khaleel.younis@epu.edu.iq and Shelan M. Maruf; \\ shelan.maruf@epu.edu.iq
}

Received 2 September 2020; Revised 26 November 2020; Accepted 1 December 2020; Published 17 December 2020

Academic Editor: Antonio G. De Lima

Copyright (c) 2020 Khaleel H. Younis et al. This is an open access article distributed under the Creative Commons Attribution License, which permits unrestricted use, distribution, and reproduction in any medium, provided the original work is properly cited.

\begin{abstract}
This experimental research investigates the effect of utilizing metakaolin (MK) on the behavior of recycled aggregate concrete (RAC). The RAC incorporates recycled coarse aggregate (RCA) originated from crushing construction and demolition waste. The investigated parameters were RCA and MK contents. Tests of workability and mechanical properties such as compressive strength, splitting tensile strength, flexural strength, and modulus of elasticity were conducted to evaluate the influence of MK on workability and mechanical behavior of RAC. In total, 19 mixes were prepared. These mixes are divided into four groups. Group zero (G0) includes a reference mix containing normal coarse aggregate (NCA) and 3 mixes made with 35\%, 70\%, and 100\% of RCA. Each one of the other three groups (G1, G2, and G3) was made with one content of the three contents of RCA, and each group includes five mixes made with the contents of $4 \%, 8 \%, 12 \%, 16 \%$, and $20 \%$ of MK. Empirical models among the mechanical properties of the RAC mixes were developed and compared with models of standard codes of practice such as ACI 318, BS 8110, and Eurocode 2. It was found that MK reduces the workability of the RAC mixes. Nonetheless, the outcomes reveal that MK can improve the compressive, splitting tensile, and flexural strengths and the elastic modulus of RAC. This strength improvement enhances as the content of MK increases. The proposed models for the mechanical properties of RAC made with MK showed good correlations. The developed model for modulus of elasticity is quite close to the Eurocode 2 model, whereas the models of ACI 318 and BS 8110 underestimate the values of the modulus of elasticity.
\end{abstract}

\section{Introduction}

As a result of the population growth, economic development, and urbanization, construction activities and demolishing works are increasing rapidly worldwide [1]. Constructing new buildings and demolishing the old ones are among these construction and demolishing activities. Although such works and activities are vital in most of the communities in the world, they cause several environmental concerns and sustainability issues that are globally recognized [2] such as the depletion of the natural resources and changes in ecosystems. Construction and demolishing activities result in massive quantities of waste which is known as construction and demolition waste (CDW). Worldwide, the annual generation of CDW is estimated at 0.5 billion tons $[3,4]$. The environmental concerns that are associated with such substantial quantitate of CDW include the use of significant parts of land to dump these wastes and the contamination of soils. To alleviate the effects of these concerns, the construction industry and researchers have examined various ways as solutions to these concerns. One solution is the utilization of CDW in concrete. It can be recycled and reused as coarse and fine aggregates. The usage of CDW as recycled coarse aggregate (RCA) in concrete can 
conserve our environment, save vast areas of land, and mitigate natural resource depletion [5].

For decades, the feasibility of the utilization of recycled aggregate in concrete production has been considered by many scholars [6]. Despite the fact that the utilization of CDW in concrete is beneficial in terms of the aforementioned environmental aspects, its use is limited $[7,8]$. The main obstacle against the use of RCA is the inferior characteristics of such aggregate in comparison with the normal aggregates. The performance of the concrete that contains such aggregate is also lower than that of the concrete made with normal aggregate $[4,9]$. This has been confirmed by previous studies $[3-5,10,11]$. The concrete made with RCA possesses low strength, high water absorption, high porosity, high shrinkage, and creep $[4,5,11]$. The content of the RCA determines the level of the decrease in the strength of the concrete. The recycled aggregate concrete (RAC) shows lower compressive strength than natural aggregate concrete (NAC) by up to $40 \%$ [12]. Additionally, the RAC exhibits lower splitting tensile strength by up to $25 \%$ [4]. Furthermore, the use of RCA in concrete results in lower flexural strength by up to $30 \%$ [5]. This behavior of RAC is the main reason behind the limitations (only 20-30) imposed by most of the international codes of practice on the RCA content that should be used to replace the NAC, in particular for structural applications [2]. The fact that the RCA particles have a heterogeneous nature in terms of its composition is the main reason causing such behavior of RAC. The RCA particles are characterized with the residual mortar attached to its surface [8]. This attached mortar possesses high porosity, low density, and microcracks which all together lead to RCA with weak and loose microstructure which in turn adversely affect the performance of RAC. The imperfections in the microstructure of the RCA particles also result in weak and uncompact interfacial transition zone (ITZ) between the recycled coarse aggregate particles and cement paste [8]. This has been recognized by several studies [7, 9, 13-15] and identified as a factor leading to low strength of RAC.

The low quality of RAC has pushed scholars to examine different methods to improve its properties and enhance the characteristics of RCA. One example is removing the residual mortar on the surface of RCA which was applied employing various approaches $[2,9]$. Although these approaches resulted in enhanced properties of RCA, they were accompanied with shortcomings like low durability, high consumption of energy, and cost issues $[4,8]$. Therefore, other studies have attempted other approaches such as the use of reactive powders that are very fine in size and possess cementitious characteristics. Reactive powders such as fly ash (FA), ground blast furnace slag (GBFS), silica fume (SF), and metakaolin (MK) have been used to improve the properties RAC [4, 16-18]. Studies have reported that such materials can enhance the mechanical properties, improve the durability, and modify the microstructure of RAC [18]. Most of these studies have attributed the improvement in the performance of RAC due to the use of these reactive powders (minerals admixtures) to the filling ability, the pozzolanic reaction, the alteration in the concrete pore structure, and compact ITZ $[4,8,19]$. Although there are many studies that dealt with improving RAC using SF, FA, and GBFS, limited work can be found when it comes to the inclusion of $\mathrm{MK}$ in such concrete.

Metakaolin $(\mathrm{MK})$ is an alumina-silicate material that is derived from clay or soils that contain high levels of kaolinite. $\mathrm{MK}$ is obtained after the clay soils are exposed to high temperatures $\left(650-900^{\circ} \mathrm{C}\right)$ for thermal activation. MK differs from other mineral admixtures (SF, FA, and GBFS) in that its production can be well controlled to minimize composition's variation and achieve high purity as well as obtain high pozzolanic reactivity $[20,21]$. MK can significantly improve the strength performance as well as the durability behavior of NAC $[20,22]$. These benefits of MK are ascribed to the pozzolanic reaction of $\mathrm{MK}$ and its high surface area (small size of its particles). The pozzolanic reaction usually develops when the $\mathrm{SiO}_{2}$ in the $\mathrm{MK}$ reacts with calcium hydrates $(\mathrm{CH})$ (a product of the cement-hydration process) with the presence of water. Such chemical reaction leads to the development of more $\mathrm{C}-\mathrm{S}-\mathrm{H}$ gel which is responsible for the strength of the cement paste. The pozzolanic reaction alters the pore structure of the cement paste as well as refines the microstructure of the concrete which can improve the performance of concrete $[20,21,23]$. There are many research studies that examined the influence of the MK on the performance of NAC in both conditions, fresh and hardened [20]. A reduction in the workability and increase in the setting time of the NCA were reported due to the usage of MK $[20,23]$. This was linked to the high surface area of the MK [20]. Furthermore, MK can improve the compressive strength of NAC at both early and late ages with more effectiveness at early ages. It was also found that the extent of the strength improvement increases with the increase of the MK content $[20,22,23]$. It was observed that the typical contents that can enhance the performance of NAC were in the range of $5-20 \%$ by cement mass [20].

Few experimental studies can be found on the effect of the use of MK on the performance of RAC [18, 24-26]. The influence of the addition of $15 \%$ of $\mathrm{MK}$ on the performance of RAC made with $50 \%$ and $100 \%$ RCA was reported in [18]. The authors found that $15 \%$ of MK improved the strength in compression, splitting tensile, and resistance to penetration of chloride by $10 \%, 18 \%$, and $32 \%$, respectively, for RAC made with 100\% RCA. Another study which was conducted in [26] reported that the inclusion of $10 \%$ of $\mathrm{MK}$ enhanced the compressive strength of RAC. Replacing $10 \%$ of cement with $\mathrm{MK}$ resulted in significant improvement in compressive strength, splitting tensile, and elastic modulus [24, 25]. Others reported strength and durability enhancement with the use of $20 \%$ of MK in RAC incorporating 100\% RCA [25].

As there are limited numbers of studies that have dealt with enhancing the behavior of RAC using MK, the current study aims at examining the outcomes of utilizing MK to help upgrading the mechanical properties of RAC. The study examines the influences of replacing the OPC with $\mathrm{MK}$ at various dosages on the behavior of RAC. To assess the influence of MK on the mechanical behavior of RAC mixtures, mechanical properties such as compressive strength, splitting tensile strength, and flexural strength of RAC were evaluated. The modulus of elasticity was also assessed for all mixtures. Utilizing the experimental results with the 
employment of the regression analysis method, empirical relationships between the mechanical properties of the RAC mixes made with MK were developed. These developed relationships were compared with models proposed by the standard codes of practice such as ACI 318, BS 8110, and Eurocode 2. The outcomes of the current study may contribute in the promotion of the feasibility of using RAC in many applications of civil engineering.

\section{Materials and Methodology}

2.1. Materials. Ordinary Portland cement (OPC) type CEMI $42.5 \mathrm{R}$ was utilized in the current research. It fulfills the specifications of Iraqi standards. It is produced by Mas Company which is based in north of Iraq (Sulaymaniyah). The chemical composition of the OPC is presented in Table 1, while the physical characteristics of the OPC are shown in Table 2.

Natural coarse aggregate and recycled coarse aggregate were used in this study. The former was river aggregate (gravel). The maximum aggregate size is $20 \mathrm{~mm}$. It had absorption capacity of $1.1 \%$ and specific density of 2.64 . The coarse recycled aggregate was recycled concrete-based aggregate derived from crushing old concrete structural elements. The RA had specific gravity and water absorption of 2.45 and $3.3 \%$, respectively. Normal sand was used as fine aggregate in the current work, and it had a maximum size of $4.75 \mathrm{~mm}$.

The metakaolin utilized in the current work was a commercial type produced by the BASF Company of chemicals. It is a reactive mineral admixture in the form of very fine white powder as can be seen in Figure 1(a). The average particle size of the metakaolin is around $1 \mu \mathrm{m}$. The chemical composition of the metakaolin is presented in Table 1, while the physical properties are presented in Table 2. Figure 1 shows a scanning electron microscopy image of the MK used in the current study.

2.2. Mixes, Variables, and Mix Proportioning. The total number of prepared and investigated mixes in this study is nineteen concrete mixtures. Table 3 shows the designation of all mixes, study's variables, and mix proportions. The variables of the mixes are the content of RCA (three contents) and the content of MK (five contents). The NCA was replaced with RCA in three contents (35\%, 70\%, and 100\%). The contents of the MK were $4 \%, 8 \%, 12 \%, 16 \%$, and $20 \%$. The investigated mixes were divided into four groups. Group zero (reference group) includes four mixes: one made with NCA and three mixes made with the three contents of RCA (35\%, 70\%, and $100 \%$ ). Each one of the other three groups was made with one content of the three contents of RCA, and each group includes five mixes made with the five contents of the MK $(4 \%, 8 \%, 12 \%$, $16 \%$, and $20 \%$ ) (see Table 3). The mixtures were prepared using the same water/binder ratio (0.46) with cement quantity of $\left(375 \mathrm{~kg} / \mathrm{m}^{3}\right)$ and water quantity of $\left(172.5 \mathrm{~kg} / \mathrm{m}^{3}\right)$. The rest of the mix proportions are shown in Table 3. An adjustment to the amount of the mix water was made in the mixes containing RCA, to take into consideration the water absorption of the RCA.
2.3. Mixing, Casting, and Curing. All experimental procedures were made in a concrete laboratory under ambient conditions. To mix the components of the concrete mixtures, a concrete tilting drum mixer that has a capacity of $0.12 \mathrm{~m}^{3}$ was employed. The mixing steps of the concrete were as follows. In the first step, the dry coarse aggregate was added to the mixer and mixed with part of the mixing water for 2 minutes. In the case of mixes with RCA, after the first step, the coarse aggregate was left in the mixer for a period of ten minutes to let the RCA absorb water to attain the saturated surface dry condition (SSD). In the second step, the sand, binders (OPC and/or $\mathrm{MK}$ ), and the remaining part of the mixing water were put in the mixes and all ingredients were mixed for 3 more minutes. When the mixing is completed, concrete was cast in different types of molds. Thereafter, proper compaction using vibrating table was conducted and all molds were covered and kept to cure in the lab conditions for $24 \mathrm{~h}$. Then, the specimens were extracted from the molds and moved to tanks containing water for further curing till the specified age for testing.

\subsection{Specimens and Tests}

2.4.1. Workability (Slump) Test. The evaluation of the workability of the fresh concrete in all mixtures was conducted through the slump test. The test was done as per BS EN 12350-2:2009 [27].

2.4.2. Compressive Strength Test. To evaluate the compressive strength of the hardened concrete, a universal hydraulic machine with $2000 \mathrm{kN}$ capacity was utilized. The test was done following the BS EN 12390-3 [28]. The test was performed on cubic specimens of $100 \mathrm{~mm}$ (see Figure 2). It was obtained at ages of 7, 28, and 90 days.

2.4.3. Splitting Tensile Strength Test. The test of splitting tensile strength was performed following the standard test of BS EN 12390-6 [29]. The same machine used for the compressive strength was also used for this test. The specimens were cylinders of $100 \times 200 \mathrm{~mm}$ as can be seen in Figure 3. For each mix, three cylinders were tested at the age of 28 days.

2.4.4. Flexural Strength Test. The test of flexural strength was performed as per the guidelines of BS EN 12390-5 [30]. Prisms of $100^{*} 100 * 500 \mathrm{~mm}$ were used to determine the flexural strength of all mixes (see Figure 4), and for each mix, after 28 days of curing, three specimens were tested.

2.4.5. Modulus of Elasticity Test. The test of modulus of elasticity was undertaken as per ASTM C469-02 [31]. Concrete cylindrical samples of $150 * 300 \mathrm{~mm}$ were made to conduct this test (see Figure 5). For all mixes, the test was conducted at the age of 28 days. 
TABLE 1: Chemical analysis of OPC and MK.

\begin{tabular}{lccccccccc}
\hline Material & $\mathrm{SiO}_{2}$ & $\mathrm{Al}_{2} \mathrm{O}_{3}$ & $\mathrm{Fe} 2 \mathrm{O} 3$ & $\mathrm{CaO}$ & $\mathrm{MgO}$ & $\mathrm{SO}_{3}$ & $\mathrm{Na}_{2} \mathrm{O}$ & $\mathrm{K}_{2} \mathrm{O}$ & $\mathrm{Na}_{2} \mathrm{Oeq}$ \\
\hline CEM I & 20.88 & 4.98 & 2.96 & 65.7 & 0.76 & 2.82 & 0.28 & 0.44 & 0.50 \\
$\mathrm{MK}$ & 57.6 & 30.1 & 6.6 & 1.0 & 0.98 & - & - & 0.58 & - \\
\hline
\end{tabular}

TABle 2: Physical characteristics of OPC and MK.

\begin{tabular}{lcc}
\hline Material & CEM I & MK \\
\hline Color & Gray & White \\
Specific gravity & 3.15 & 2.5 \\
Fineness $(\mathrm{cm} 2 / \mathrm{g})$ & 2400 & 12800 \\
\hline
\end{tabular}

\section{Results}

3.1. Workability (Slump) Test. Workability of all concrete mixtures was assessed by the slump test. Table 4 illustrates the slump values of all mixes. It was observed that the workability of mixes encompassing RCA in G0 is lower than that of the reference mix (N00). The slump values decreased from $125 \mathrm{~mm}$ for the mix with NCA to 100,85 , and $80 \mathrm{~mm}$ when the NCA was replaced with $30 \%, 70 \%$, and $100 \%$ of RCA. This decrease in slump value depends on the RCA content (when the RCA content increases, the slump value reduces). The adverse effect of the use of RCA in concrete is also reported by others $[4,8,32]$. This slump value decrease can be partly related to the rough surface of the RCA and mainly to the high absorption capacity of the RCA compared with that of the NCA $[4,32]$ (see Table 4).

The effect of the use of MK on the workability of the mixes made with RCA (mixes of G1, G2, and G3) is shown in Figure 6. It can be seen that the content of the MK adversely affects the slump values of these regardless of the percentage of the RCA. There is a general decrease trend in the workability of the mixes made with $30 \%$, $70 \%$, and $100 \%$ RCA as the content of the MK increases as can be seen in Figure 7. For example, for mixes in G1 $(\mathrm{RCA}=35 \%)$, these mixes lost about 10\%, 15\%, 20\%, 20\%, and $30 \%$ of their workability (compared to the reference group) when $4 \%, 8 \%, 12 \%, 16 \%$, and $20 \%$ of the OPC were replaced with MK. Higher ratios of workability loss were recorded with mixes with higher contents of RCA (70\% and $100 \%$ in G2 and G3) (see Figure 7). The drop in the workability of concrete due to adding $\mathrm{MK}$ was also reported in $[20,22,24]$. This workability loss is attributed to the very small size of the particles of MK compared to the particles of the OPC, which can be clearly identified in Table 2 when we compare the surface area of the two powders. Higher surface area requires more water to achieve suitable workability [20]. One more reason could be the forces of van der Waals, which can be considered as the source to the development of agglomeration and electrostatic attraction between the particles of any powder, and these are more dominant with powders having high surface area [33]. These agglomeration and electrostatic attraction hinder the movement of the matrix, hence reducing the workability of concrete.
3.2. Compressive Strength. Table 4 shows the outcomes of the compressive strength test at the ages of 7,28, and 90 days of all mixes. The results at 28 days, which are the average of three specimens for each mix, are also presented in Figure 8. As far as the results of the reference group (G0) are concerned, generally mixes with RCA exhibited lower compressive strength than mix N00 regardless of the age of the concrete at testing time. The degree of strength reduction depends on the content of RCA. For example, at the age of 28 days, the strength of the reference mix which includes NCA decreased by $12 \%, 20 \%$, and $30 \%$ when the NCA was replaced by $35 \%, 70 \%$, and $100 \%$ of RCA as it is clear in Figure 8. A decrease in strength due to replacing NCA by RCA was reported by others $[4,10,14]$. This decrease in strength can be related to the lower quality of the RCA particles compared to NCA. The lower quality is due to the adhered mortar existing on the surface of the RCA which is characterized with microcracks and voids, hence resulting in low strength and stiffness and high water absorption and porosity concrete [14]. This nondense adhered mortar also deteriorates the cement paste and the RCA bond, leading to the development of weak interfacial transition zone (ITZ) $[8,34,35]$. Indeed, weak ITZ increases the propagation of the cracking process under loading, causing early failure and lower strength.

The influence of the use of $\mathrm{MK}$ on the compressive strength of concrete mixtures made with RCA (in groups G1, G2, and G3) can be seen in Table 4 and Figure 8. The general trend that can be identified is a positive strength enhancement regardless of the content of both RCA and MK. The influence of the percentage of MK on the compressive strength and the recycled aggregate concretes is presented and discussed based on the normalized strength. The strength of the mixes is normalized with the reference mixes (G0): N00, R350, R700, and R1000. Normalized strength means that the average compressive strength of the mix is divided on the average compressive strength of the reference mix. The normalized strengths to that of the N00 mix are illustrated in Figure 9, while the normalized strength of the mixes with RCA that contain MK to that of RCA mixes without MK are presented in Figure 10.

The normalized strength of the mixes made with $35 \%$, $70 \%$, and $100 \%$ RCA to that of the mix N00 are shown in Figures 9(a), 9(b) and 9(c). Regardless of the content of RCA, the general strength enhancement in the compressive strength of the RCA mixtures due to the use of MK can be observed. The strength enhancement increases with the increase in the content of $\mathrm{MK}$, in particular at RCA content of 35\%, as can be seen in Figures 9(a), 9(b), and 9(c). However, the optimum content of MK that leads to a compressive strength equal/or comparable strength to that of the mix N00 (made with NCA) varies according to the 


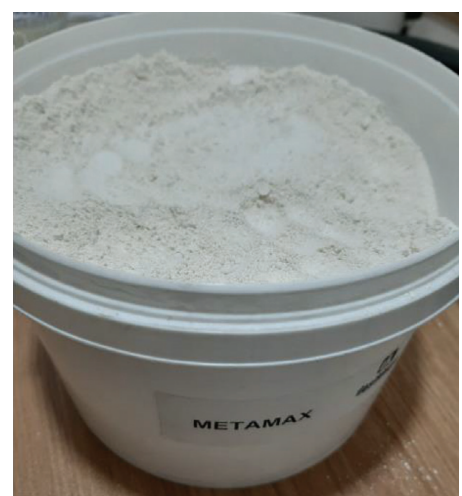

(a)

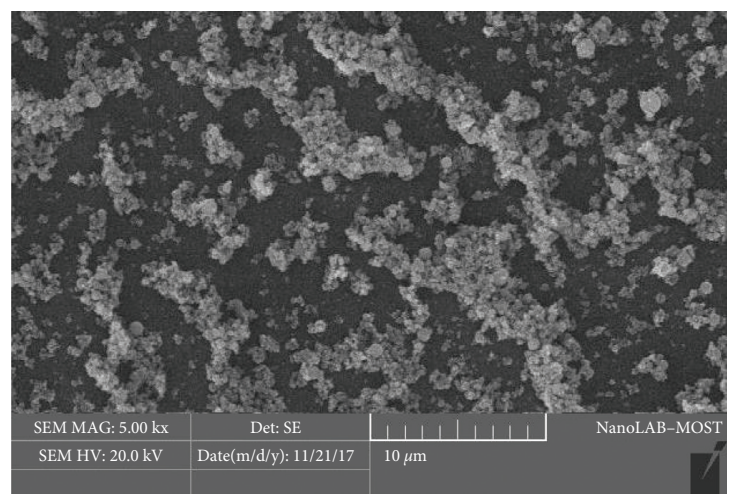

(b)

FIGURE 1: Metakaolin used in current study. (a) Metakaolin powder. (b) Scanning electron microscopy image.

TABLE 3: Mix designation and proportioning.

\begin{tabular}{|c|c|c|c|c|c|c|c|c|}
\hline Group & $\begin{array}{c}\text { Mix } \\
\text { designation } \\
\end{array}$ & $\begin{array}{c}\% \text { of } \\
\text { metakaolin }^{\mathrm{a}}\end{array}$ & Cement & Metakaolin & Water & $\begin{array}{c}\text { Coarse Agg. } \\
\text { (natural) }\end{array}$ & $\begin{array}{c}\text { Coarse } \\
\text { Agg.(recycled) } \\
\end{array}$ & Fine Agg. \\
\hline \multirow{4}{*}{$\begin{array}{l}\text { Reference group or } \\
\text { G0 }\end{array}$} & N00 & 0 & 375 & 0 & 172.5 & 1092 & 0 & 711 \\
\hline & R350 & 0 & 375 & 0 & 172.5 & 710 & 359 & 711 \\
\hline & $\mathrm{R} 700$ & 0 & 375 & 0 & 172.5 & 328 & 718 & 711 \\
\hline & $\mathrm{R} 1000$ & 0 & 375 & 0 & 172.5 & 0 & 1026 & 711 \\
\hline \multirow{5}{*}{ G1 } & R354 & 4 & 360 & 15 & 172.5 & 710 & 359 & 711 \\
\hline & R358 & 8 & 345 & 30 & 172.5 & 710 & 359 & 711 \\
\hline & $\mathrm{R} 3512$ & 12 & 330 & 45 & 172.5 & 710 & 359 & 711 \\
\hline & $\mathrm{R} 3516$ & 16 & 315 & 60 & 172.5 & 710 & 359 & 711 \\
\hline & $\mathrm{R} 3520$ & 20 & 300 & 75 & 172.5 & 710 & 359 & 711 \\
\hline \multirow{5}{*}{ G2 } & R704 & 4 & 360 & 15 & 172.5 & 328 & 718 & 711 \\
\hline & R708 & 8 & 345 & 30 & 172.5 & 328 & 718 & 711 \\
\hline & R7012 & 12 & 330 & 45 & 172.5 & 328 & 718 & 711 \\
\hline & R7016 & 16 & 315 & 60 & 172.5 & 328 & 718 & 711 \\
\hline & R7020 & 20 & 300 & 75 & 172.5 & 328 & 718 & 711 \\
\hline \multirow{5}{*}{ G3 } & R1004 & 4 & 360 & 15 & 172.5 & 0 & 1026 & 711 \\
\hline & R1008 & 8 & 345 & 30 & 172.5 & 0 & 1026 & 711 \\
\hline & R10012 & 12 & 330 & 45 & 172.5 & 0 & 1026 & 711 \\
\hline & R10016 & 16 & 315 & 60 & 172.5 & 0 & 1026 & 711 \\
\hline & R10020 & 20 & 300 & 75 & 172.5 & 0 & 1026 & 711 \\
\hline
\end{tabular}

${ }^{\mathrm{a} B y}$ cement mass.

content of RCA (see Figure 9). For example, for the mixes made with $35 \%$ RCA, a content of MK which is equal to $12 \%$ is enough to get normalized strength of 1.0 which means similar strength to that of mix N00 (see Figure 9(a))). This also means that the use of $12 \%$ of MK instead of OPC can compensate the $12 \%$ compressive strength loss of mix N00 when $35 \%$ of NCA was replaced with RCA. Figure 9(b)) shows that for the mix containing $70 \%$ of RCA, to reach a comparable strength to that of mix N00, 20\% of the OPC should be replaced with MK. For the mix made with $100 \%$ RCA, even $20 \%$ of MK did not result in comparable strength to the reference mix as $20 \%$ of $\mathrm{MK}$ led to a normalized strength of 0.9 as can be seen in Figure 9(c). This means that when the NCA is fully replaced with RCA, $90 \%$ of the compressive strength of the mix N00 can be obtained by replacing $20 \%$ of the OPC with MK.

The beneficial influence of utilizing $\mathrm{MK}$ on the compressive strength of the mixes containing RCA can be justified by three mechanisms. The first mechanism is physical while the second and the third mechanisms are chemical [8]. The physical one can be elucidated by the filling capability of MK particles. The very fine particles of the MK as mineral admixture can play a key role in filling microvoids and pores on the surface of the RCA and in modifying the microstructure of the concrete and making it denser [22]. Indeed, this mechanism helps in enhancing the density of the concrete and hence improving the compressive strength of the concrete. The chemical mechanism can be described by the pozzolanic reaction of the MK [20]. This reaction usually develops due to the high content of silicon dioxide in the MK. The silicon dioxide reacts with the calcium hydroxide $(\mathrm{CH})$ which is a part of production of the cement hydration; this reaction leads to the production of more calcium-silicate-hydrates $(\mathrm{C}-\mathrm{S}-\mathrm{H})$, the main production that enhances the strength of concrete [9]. Therefore, this chemical mechanism also results in improving the 


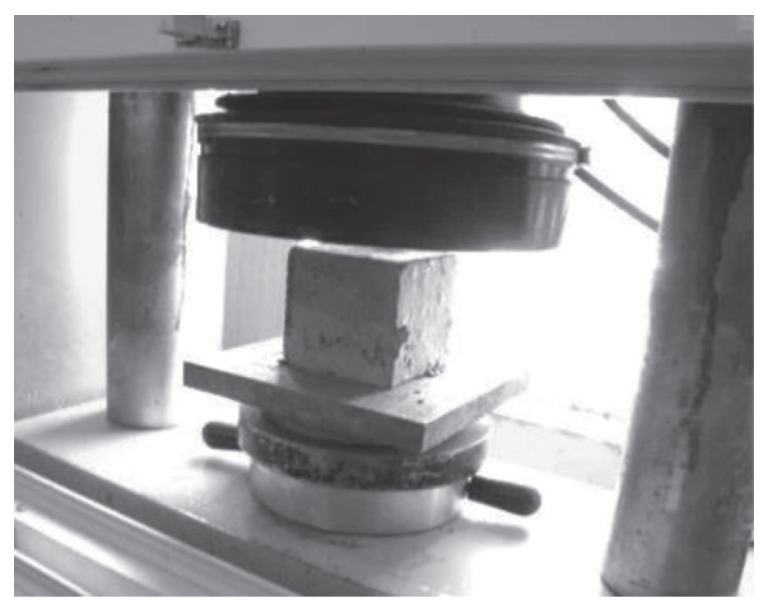

Figure 2: Specimen under compression machine.

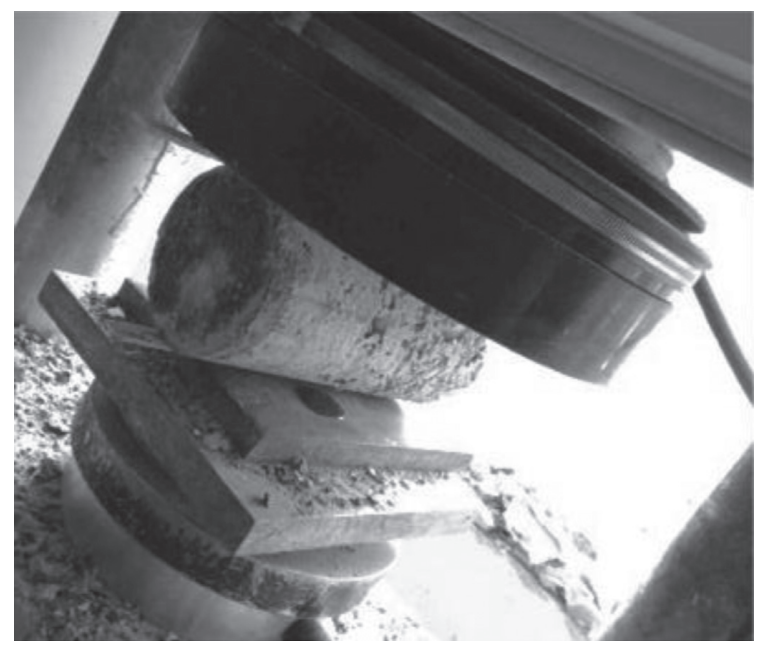

FIgURE 3: Specimen prepared for splitting tensile test.

compressive strength of the RCA mixes. Thus, this is why the level of the strength improvement rises as the content of the MK increases, as can be seen in Figure 9. The third mechanism is by speeding up the reaction between the water and the cement particles which is well known as hydration process. This increase in the rate of the hydration process is due to the high surface area of the small particles of the MK. The acceleration of the hydration process acts as a booster for the pozzolanic reaction, hence improving the compressive strength of concrete [20].

The normalized strength of the mixes made with $\mathrm{MK}$ and $35 \%, 70 \%$, and $100 \%$ RCA to that of the mixes without MK is shown in Figures 10(a), 10(b), and 10(c). Regardless of the content of RCA, a clear rise in the compressive strength of the RCA mixtures due to the addition of MK can be observed. This strength increase is directly connected to the increase in the content of the MK (see Figures 10(a), 10(b), and 10(c)). Nonetheless, the extent of strength increase also depends on the RCA content. For instance, at 35\% of RCA content, the strength increase can reach up to $19 \%$ when the OPC was replaced with

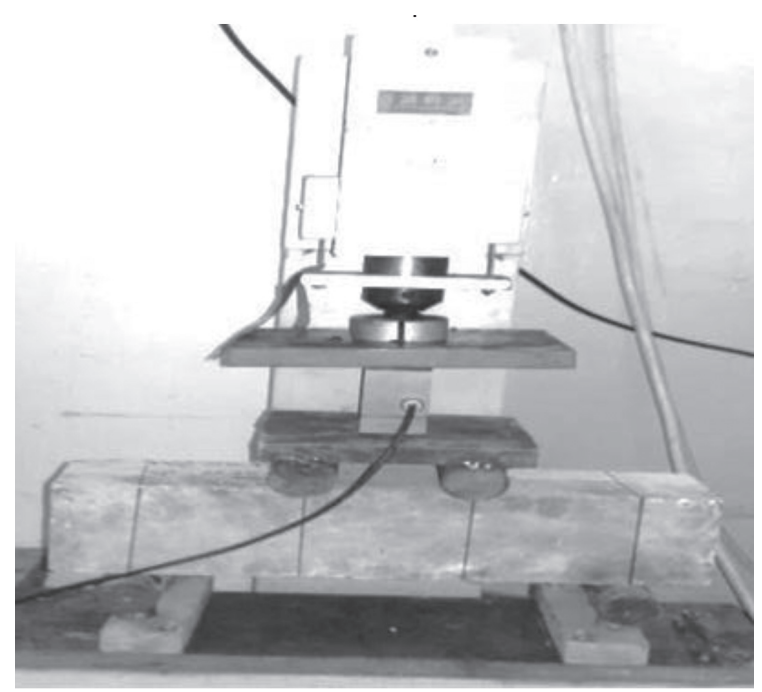

FIgURE 4: Specimen under bending machine.

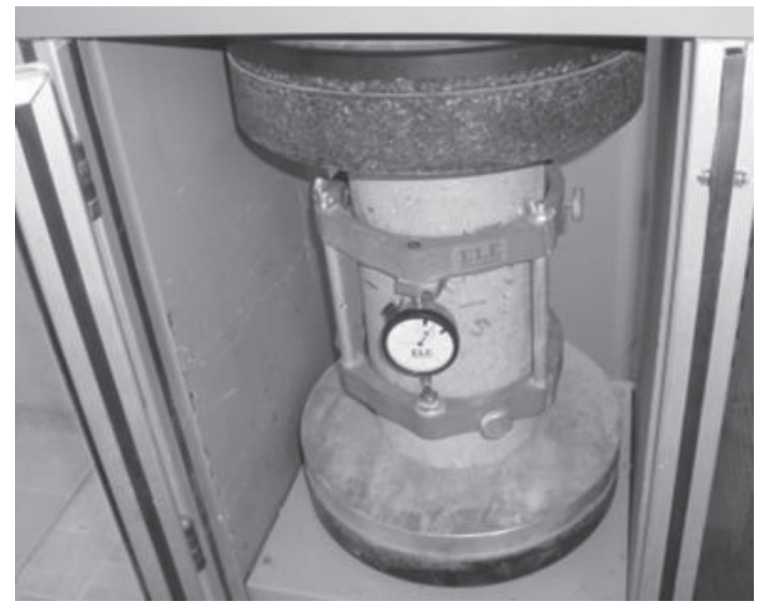

FIGURE 5: Specimen prepared for the modulus of elasticity test.

$20 \%$ of MK, whereas at the same content of the MK, the strength increase rises to $23 \%$ and $29 \%$ for the RCA of $70 \%$ and $100 \%$, respectively (see Figure 10).

This compressive strength enhancement could be due to the strengthening of the RCA by the MK. This strengthening can be achieved by (1) filling up the microcracks and voids on the surface of the RCA and (2) eliminating the porosity of the adhered mortar on the RCA surface. Moreover, the improvement of the quality of RCA surface not only increases the strength of the RCA itself but also enhances the ITZ between the $\mathrm{RCA}$ and the cement paste. Another reason for the strength enhancement of the RAC mixes could be the nucleation effect since the existence of several zones of nucleation could help in providing a more uniform and homogenized distribution of the strength-responsible gel C-S-H in the concrete [36]. This, in turn, leads to a denser pore structure of the concrete resulting in higher strength of concrete. These reasons with the pozzolanic reaction effect can together justify the strength enhancement of the RCA mixes incorporating MK compared to those without $\mathrm{MK}$. 
TABLE 4: Results of workability and compressive strength of all mixes.

\begin{tabular}{|c|c|c|c|c|c|}
\hline \multirow{2}{*}{ Group } & \multirow{2}{*}{ Mix designation } & \multirow{2}{*}{ Slump (mm) } & \multicolumn{3}{|c|}{ Compressive strength (MPa) } \\
\hline & & & 7 days & 28 days & 90 days \\
\hline \multirow{4}{*}{ Reference group or G0 } & N00 & 125 & 33.2 & 44.8 & 49.7 \\
\hline & R350 & 100 & 27.6 & 39.4 & 42.6 \\
\hline & R700 & 85 & 24.6 & 35.7 & 39.3 \\
\hline & $\mathrm{R} 1000$ & 80 & 21.4 & 31.4 & 34.2 \\
\hline \multirow{5}{*}{ G1 } & R354 & 90 & 27.5 & 41.0 & 45.5 \\
\hline & R358 & 85 & 29.1 & 42.2 & 47.6 \\
\hline & $\mathrm{R} 3512$ & 80 & 31.0 & 44.9 & 50.3 \\
\hline & $\mathrm{R} 3516$ & 80 & 30.4 & 45.3 & 52.6 \\
\hline & $\mathrm{R} 3520$ & 70 & 33.3 & 46.9 & 55.3 \\
\hline \multirow{5}{*}{ G2 } & R704 & 80 & 26.7 & 38.2 & 42.0 \\
\hline & R708 & 75 & 26.9 & 39.6 & 44.8 \\
\hline & R7012 & 70 & 28.6 & 42.1 & 48.4 \\
\hline & R7016 & 60 & 29.8 & 43.2 & 50.1 \\
\hline & R7020 & 60 & 30.3 & 43.9 & 50.9 \\
\hline \multirow{5}{*}{ G3 } & R1004 & 80 & 22.3 & 33.3 & 37.9 \\
\hline & R1008 & 75 & 23.9 & 35.2 & 40.4 \\
\hline & R10012 & 75 & 25.8 & 37.4 & 43.7 \\
\hline & R10016 & 65 & 26.5 & 38.9 & 45.9 \\
\hline & R10020 & 60 & 29.6 & 40.5 & 48.5 \\
\hline
\end{tabular}

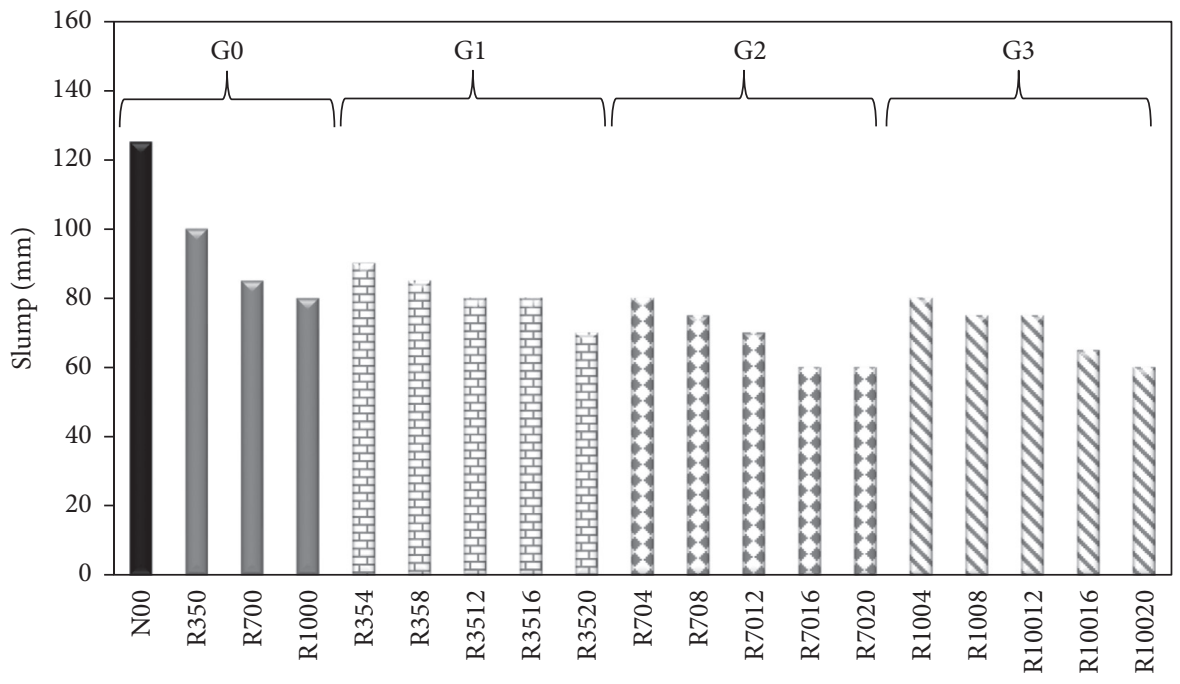

Type of concrete mix

Figure 6: Slump values of all mixes.

The rate of the strength increase is also related to the content of MK. This rate is high up to $12 \%$ of MK content, but after that, this rate slows down as can be seen in Figure 11 . This behavior is similar for all RCA contents (35\%, $70 \%$, and $100 \%$ ).

The influence of curing time or the age of concrete at testing on the development of the compressive strength of the mixtures is presented in Figure 12. This figure shows the rate of strength development over time for the mixes with and without MK. Figure 12(a)) shows the strength development of the reference mixes (group G0) made without MK, while Figure 12(b)) depicts the strength development for the mixes made with $20 \%$ MK. From Figures 12(a) and 12(b), it can be observed that rate of strength development for the mixes including MK is higher than those without MK particularly after the age of 28 days and up to 90 days. Thus, the effect of MK on the strength of the RCA mixes is more influential at early ages than later ages. This is very clear in Figure 12(c)) which compares the rate of development of strength of the mixes with and without MK.

3.3. Splitting Tensile Strength. The splitting tensile strength results of the cylindrical samples after curing for 28 days of mixes made with and without MK are presented in Table 5. The normalized strength (to the mix N00 and to the mixes of RCA without MK) is also presented in Table 5. The splitting 


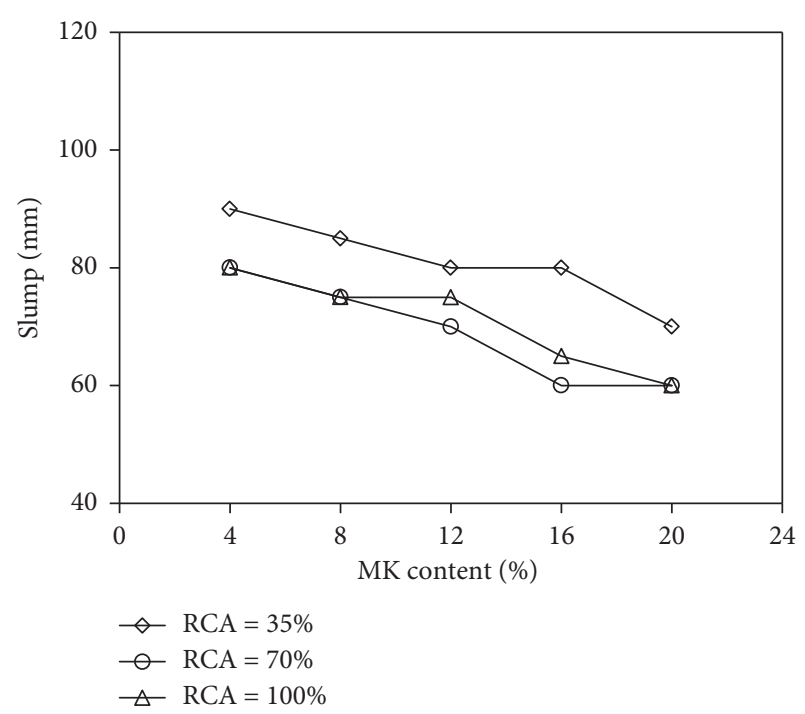

FIGURE 7: Effect of MK content on the slump values at various contents of RCA.

tensile values $(\mathrm{MPa})$ are also shown in Figure 13. These results represent the average of three cylindrical samples.

In the reference group (G0), the trend of the results of the splitting tensile strength is similar to the trend of the results of the compressive strength. The splitting tensile strength of mixes made with RCA exhibited lower strength than that of the reference mix N00. The splitting tensile strength of mixes R350, R700, and R1000 dropped to $3.94,3.57$, and $3.45 \mathrm{MPa}$ compared to $4.03 \mathrm{MPa}$ of mix N00. This means that the concrete lost about $2 \%, 11 \%$, and $14 \%$ of its strength when the NCA was replaced with RCA at contents of $35 \%, 70 \%$, and $100 \%$, respectively, as shown in Table 5 . Similar behavior was also observed by other studies $[5,14]$ for recycled coarse aggregate concrete. The loss of splitting tensile strength of the mixes made with RCA is because of the weaknesses in the RCA particles related to the adhered mortar which is considered as weak and cracked surface. The weak bond between the cement paste and the RCA particles caused by the loosely attached mortar also results in a weak ITZ, thus extending the possibility of the existence of flaws and weak points that promote cracking in these zones and decreasing the splitting tensile strength of the concrete $[4,8,34]$.

The results of the mixes in groups G1, G2, and G3 reveal the positive effect of using various contents of MK on the splitting tensile strength of these mixes (see Table 5). Regardless of the content of RCA, low contents of MK ( $4 \%$ and $8 \%)$ show no or very slight strength enhancement, whereas high contents $(12 \%, 16 \%$, and $20 \%)$ resulted in strength enhancement that reached comparable values to that of the reference mix. For example, the tensile strength of mix made with $35 \%$ of RCA increased to reach a comparable value to that of mix N00 only at $20 \%$ of MK, while for the mixes made with $70 \%$ and $100 \%$ RCA, MK contents of $16 \%$ and $20 \%$ led to the same strength of mix N00. On the other hand, at the MK content of $20 \%$, the normalized tensile strength of the mixes with $35 \%, 70 \%$, and $100 \%$ RCA was about $1.06,1.11$, and 1.15 , respectively, compared to the strength of the same mixes without MK.

The better splitting tensile strength due to the inclusion of $\mathrm{MK}$ is because of the strengthening of the top surface of the RCA by the filling ability of the very fine particles of the $M K$. Furthermore, the contribution of the MK in enhancing the ITZ is also a factor that can enhance the splitting tensile strength of concrete. Moreover, the pozzolanic reaction of the MK can also positively affect the splitting tensile strength of the RCA $[8,20]$.

3.4. Flexural Strength. The results of the flexural strength measured on prisms with dimensions of $500^{*} 100^{*} 100 \mathrm{~mm}$ and loaded using four-point bending test are presented in Table 6 . These results are the average of three samples tested after 28 days of curing. The normalized strength (to the mix N00 and to the mixes of RCA without MK) is also illustrated in Table 6. Figure 14 shows the flexural strength values in MPa.

The mixes made with recycled coarse aggregates in the reference group showed lower flexural strength than that of mix N00. The higher the content of the RCA, the higher the loss of the flexural strength compared to mix N00. For example, the flexural strength decreased from $5.02 \mathrm{MPa}$ to $4.65,4.25$, and $4.08 \mathrm{MPa}$ when the NCA was replaced by $35 \%, 70 \%$, and $100 \%$ of RCA, respectively, as can be seen in Table 6 and Figure 14. Hence, the concrete loses about 7\%, $15 \%$, and $19 \%$ of its flexural strength when $35 \%, 70 \%$, and $100 \%$ of the NCA were replaced by RCA, respectively. As explained in Sections 3.3 and 3.4, the drop in the flexural strength due to the inclusion of the RCA can be attributed to loose and cracked surface of the RCA, the weak bond between the RCA and the cement paste, and the porous ITZ $[13,14]$. All these reasons can act as early failure initiatives leading to lower flexural strength.

Nonetheless, these reductions in flexural strength of the mixes made with RCA can be compensated by replacing the OPC with MK as can be seen in Table 6. The use of MK improves the flexural strength of these mixes almost at all contents of the MK but the level of improvement depends on the content of RCA. For instance, at 35\% of RCA, even at low contents of MK ( $4 \%, 8 \%$, and $12 \%)$, comparable (to that of the reference mix N00) flexural strength can be achieved, whereas high contents of MK (16\% and 20\%) are needed to get the same comparable flexural strength (see the normalized strength in Table 6) for the mixes made with 70\% and $100 \%$ RCA. Comparison of the results of the RCA mixes made with and without MK reveals that all contents of MK increase the flexural strength of these mixes, and the higher the content of MK, the higher the flexural strength of the mix. At $20 \%$ of the MK, the flexural strength of the mixes made with $35 \%, 70 \%$, and $100 \%$ of RCA increased by $16 \%$, $15 \%$, and $22 \%$, respectively, compared to the same mixes but without MK. This beneficial effect of the MK on the RCA concrete is also reported in $[20,24]$. The flexural strength improvement can be elucidated by the same explanations previously mentioned in Sections 3.2 and 3.3 which are the strengthening of the RCA particles, the refinement in the 


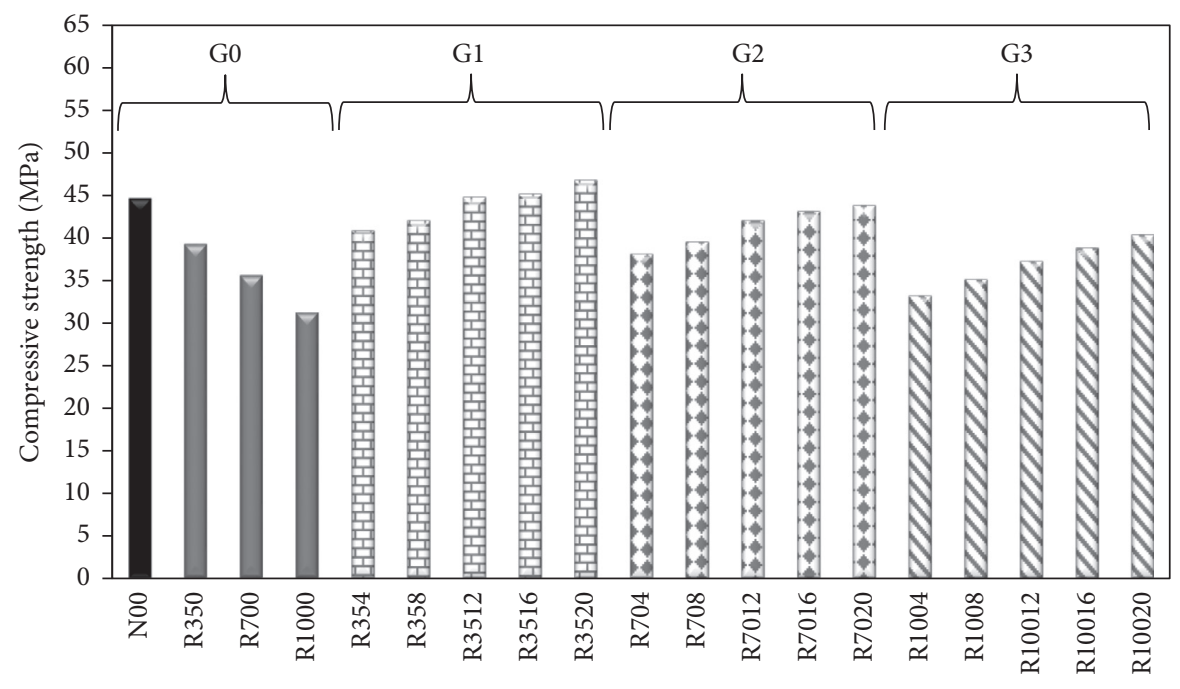

Type of concrete mix

Figure 8: Compressive strength of all mixes at age of 28 days.

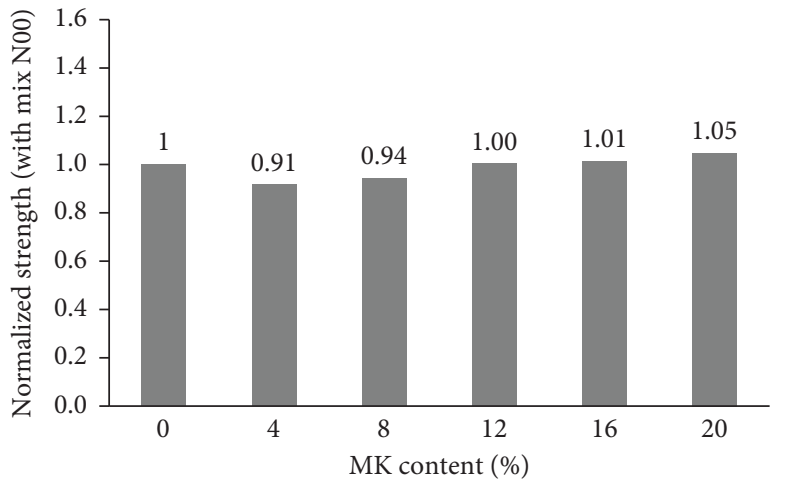

(a)

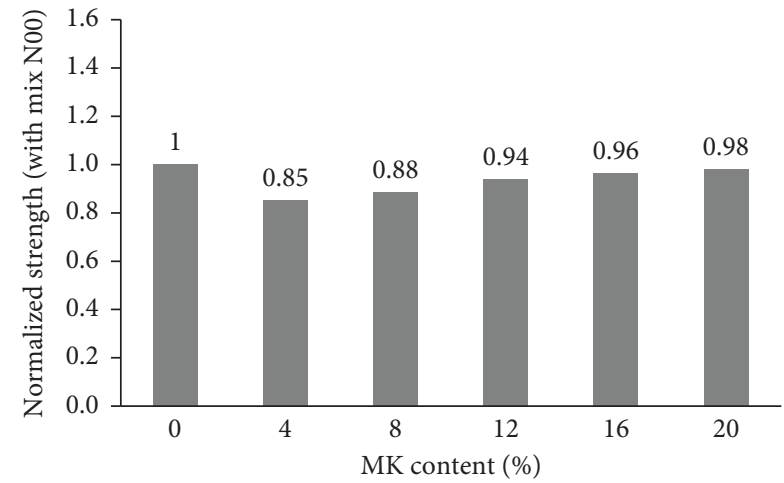

(b)

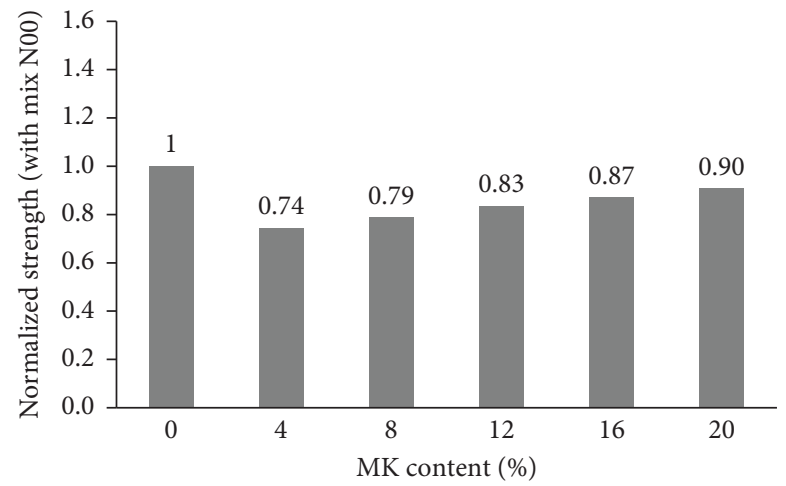

(c)

Figure 9: Normalized strength (with mix N00) for mixes. (a) RCA $=35 \%$. (b) RCA $=70 \%$. (c) RCA $=100 \%$.

microstructure of the paste, and the densification in the interfacial transition zone.

3.5. Modulus of Elasticity (Ec). The results of the elastic modulus determined using cylindrical concrete samples are illustrated in Table 7 . These results are the average of three samples tested at the age of 28 days. The normalized strength (to the mix N00 and to the mixes of RCA without MK) is also shown in Table 7. Figure 15 shows the values of the elastic modulus in $\mathrm{GPa}$.

Figure 15 shows that the modulus of elasticity of the RCA mixes in the reference group (G0) is lower than the value of the mix N00. The elastic modulus of the mix N00 reduced 


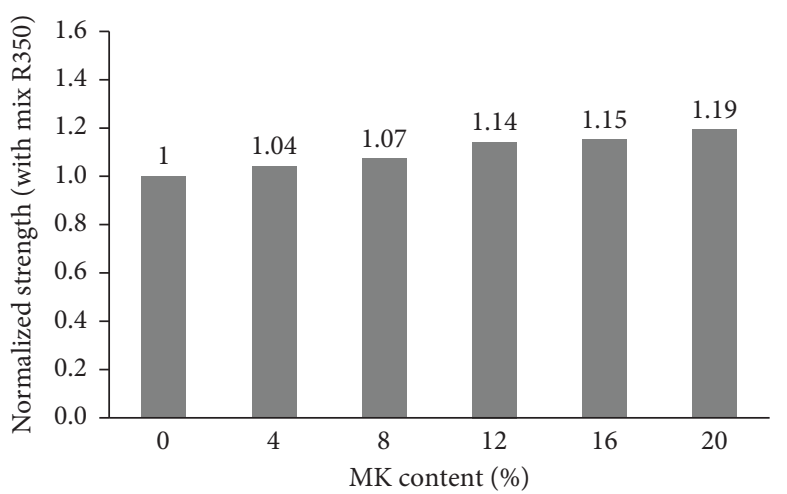

(a)

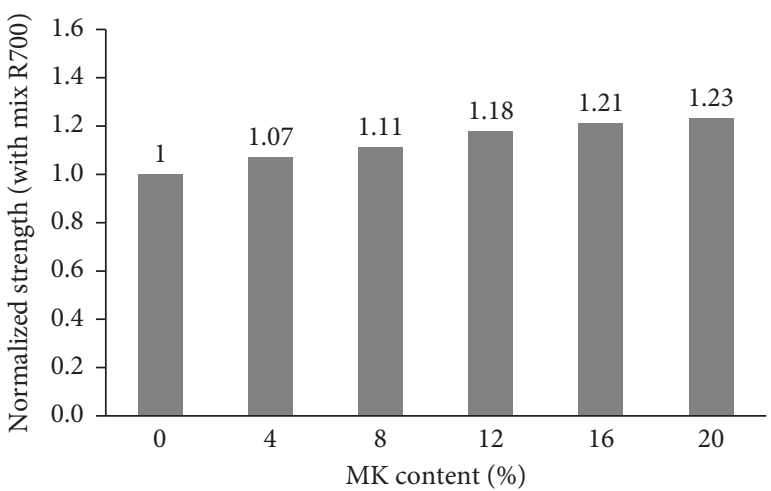

(b)

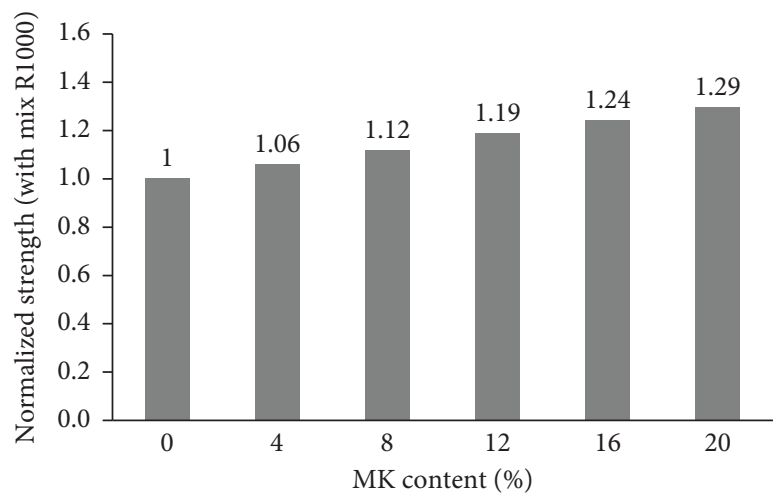

(c)

FIGURE 10: Normalized strength (with the mix of RCA without MK) for mixes. (a) RCA $=35 \%$. (b) RCA $=70 \%$. (c) RCA $=100 \%$.

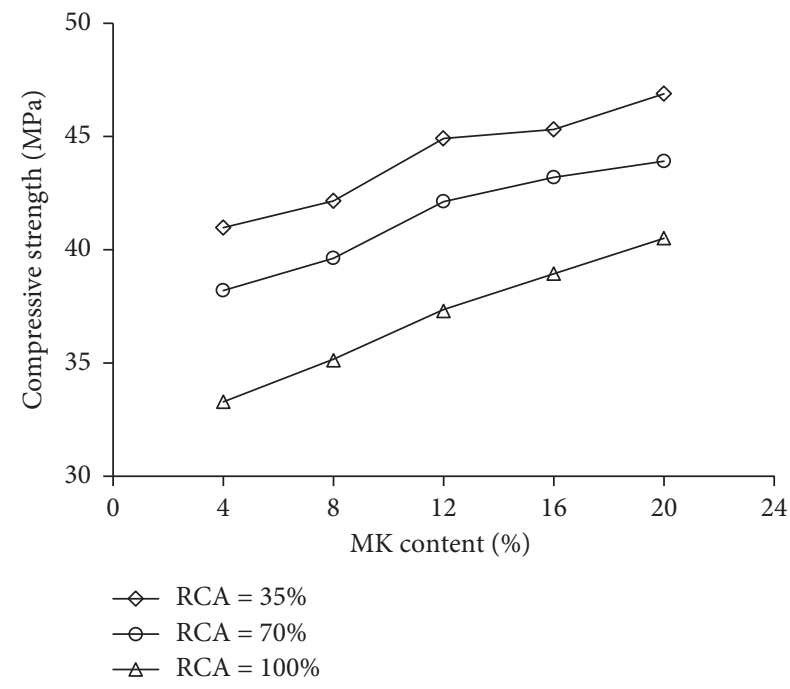

FIGURE 11: Influence of the MK on the compressive strength of the RCA mixes.

from 37.4 GPa to 32.1, 31.0, and 30.1 GPa when the NCA was replaced with $35 \%, 70 \%$, and $100 \%$ of RCA, respectively. As can be seen, the reduction in elastic modulus depends on the RCA content; the higher the RCA content, the higher the drop in modulus of elasticity. This reduction due to the use of RCA represents $14 \%, 17 \%$, and $20 \%$ for the R350, R700, and R1000 compared to the elastic modulus of mix N00. The reduction in the modulus of elasticity due to the use of RCA is lower than the reduction in the compressive strength. At $100 \%$ of RCA, the compressive strength reduced by $30 \%$, whereas the modulus of elasticity decreased by $20 \%$.

The loss of stiffness (elastic modulus) as a result of using RCA could be due to the characteristics of the RCA particles. As mentioned previously, these particles are inherently weak because of the porous nature of its surface which results from microcracks and voids in attached mortar existing on the top surface of these particles. The porous ITZ caused by the weak bond between the RCA and the cement paste also contributes to the loss of the elastic modulus of RCA mixes. Indeed, these flaws (cracks and voids) decrease the ability to withstand loads and weaken the stiffness of the concrete leading to lower elastic modulus $[4,8,13]$.

The advantageous effect of the partial substitution of OPC with MK on the elastic modulus is clear in Table 7. The improvement of the modulus of elasticity increases as the MK content increases. The higher values were obtained at $20 \%$ of MK content. For example, at $20 \%$ of MK, the elastic modulus of the mixtures with 35\%,70\%, and 100\% RCA achieved 98\%, $96 \%$, and $89 \%$ of the that of the reference mix N00; this means that the loss of elastic modulus of these mixes of RCA was reduced from $14 \%, 17 \%$, and $20 \%$ to $2 \%, 4 \%$, and $11 \%$ when $20 \%$ of MK was used (see normalized strength in Table 7 ). The improvement in the modulus of elasticity of the RCA mixes due to the inclusion of MK could be due to the modification on the 


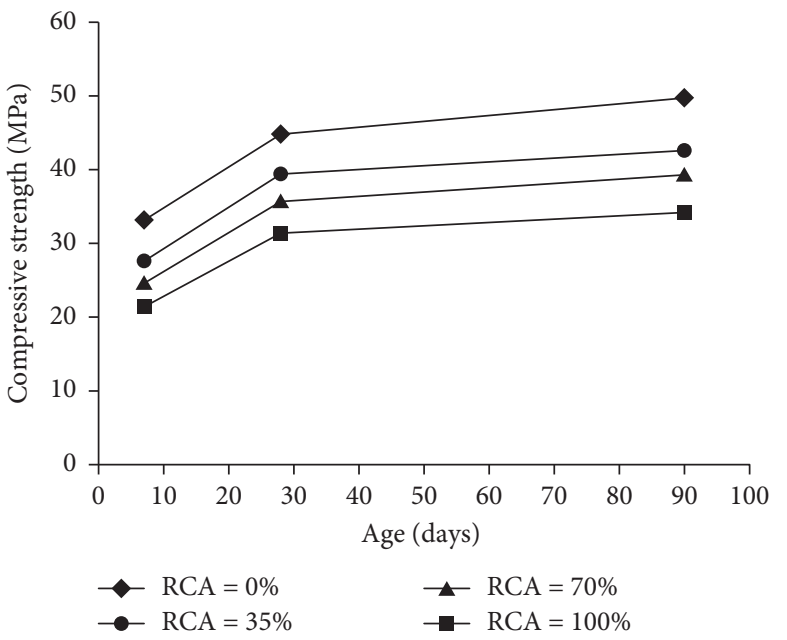

(a)

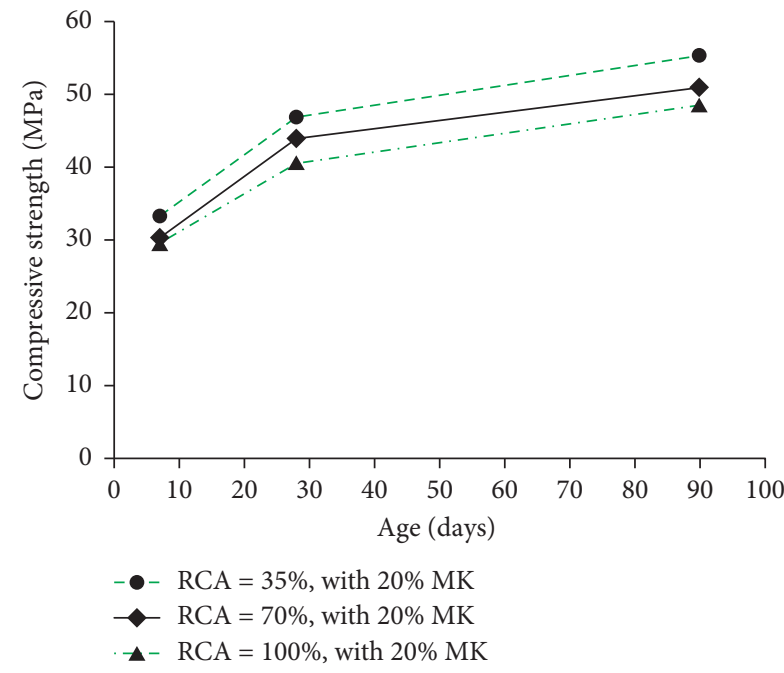

(b)

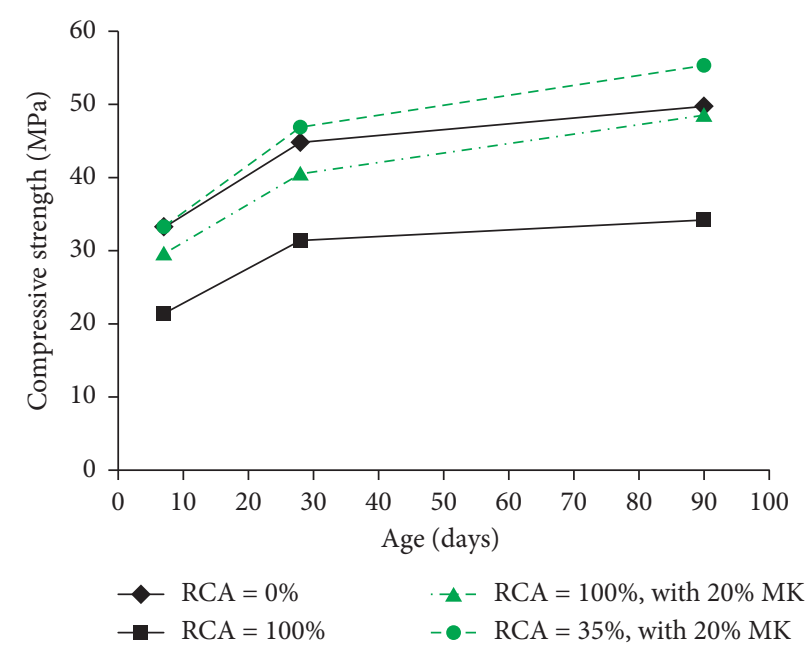

(c)

Figure 12: Strength development over time. (a) Mixes without MK. (b) Mixes with 20\% of MK. (c) Comparing several mixes in (a) and (b).

TABLE 5: Results of splitting tensile strength (strength values and normalized strength).

\begin{tabular}{|c|c|c|c|c|}
\hline \multirow{2}{*}{ Group } & \multirow{2}{*}{ Mix designation } & \multicolumn{3}{|c|}{ Splitting tensile } \\
\hline & & Strength $(\mathrm{MPa})$ & Normalized (to mix N00) & Normalized (to mixes: R350/R700/R1000) \\
\hline \multirow{4}{*}{ Reference group or G0 } & N00 & 4.03 & 1 & - \\
\hline & $\mathrm{R} 350$ & 3.94 & 0.98 & 1 \\
\hline & $\mathrm{R} 700$ & 3.57 & 0.89 & 1 \\
\hline & $\mathrm{R} 1000$ & 3.45 & 0.86 & 1 \\
\hline \multirow{5}{*}{ G1 } & R354 & 3.69 & 0.91 & 0.94 \\
\hline & R358 & 3.71 & 0.92 & 0.94 \\
\hline & $\mathrm{R} 3512$ & 3.91 & 0.97 & 0.99 \\
\hline & R3516 & 3.85 & 0.96 & 0.98 \\
\hline & $\mathrm{R} 3520$ & 4.17 & 1.03 & 1.06 \\
\hline \multirow{5}{*}{ G2 } & R704 & 3.51 & 0.87 & 0.98 \\
\hline & R708 & 3.57 & 0.88 & 1.00 \\
\hline & R7012 & 3.79 & 0.94 & 1.06 \\
\hline & R7016 & 3.93 & 0.97 & 1.10 \\
\hline & R7020 & 3.97 & 0.99 & 1.11 \\
\hline \multirow{5}{*}{ G3 } & R1004 & 3.26 & 0.81 & 0.94 \\
\hline & R1008 & 3.80 & 0.94 & 1.10 \\
\hline & R10012 & 3.74 & 0.93 & 1.08 \\
\hline & R10016 & 3.97 & 0.98 & 1.15 \\
\hline & R10020 & 4.05 & 1.00 & 1.17 \\
\hline
\end{tabular}




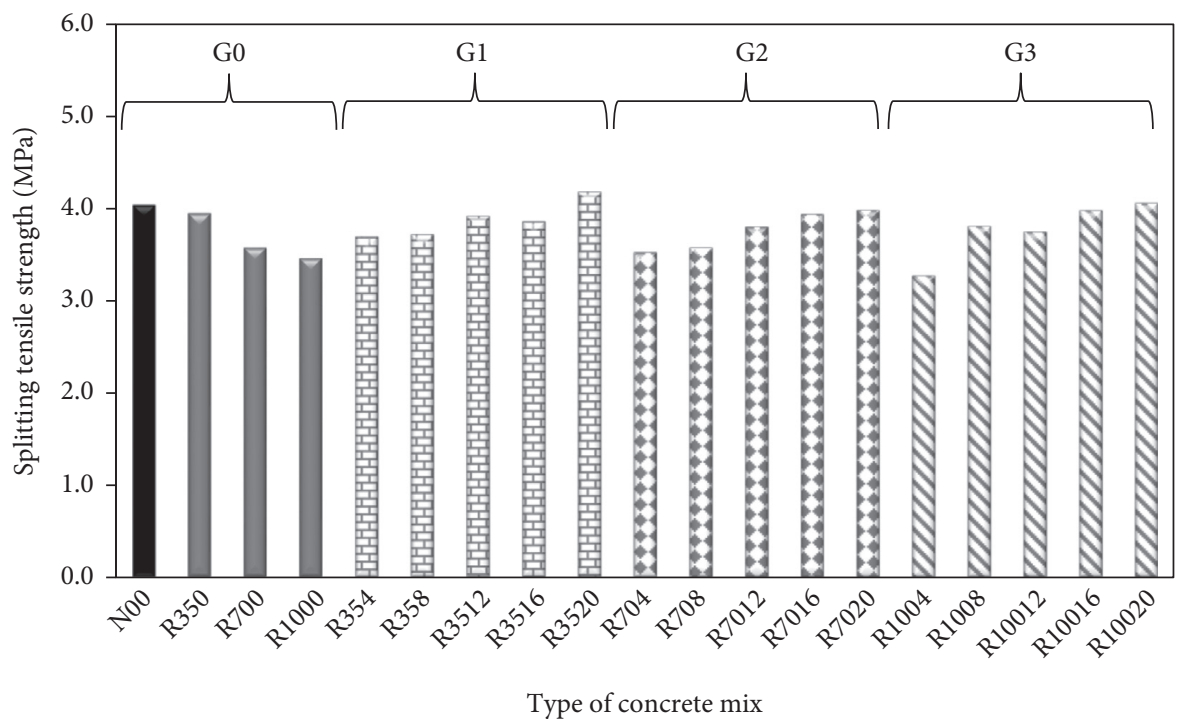

Figure 13: Splitting tensile strength at the age of 28 days.

TABLE 6: Results of flexural strength of all mixes (strength values and normalized strength).

\begin{tabular}{|c|c|c|c|c|}
\hline \multirow{2}{*}{ Group } & \multirow{2}{*}{ Mix designation } & \multicolumn{3}{|c|}{ Flexural } \\
\hline & & Strength $(\mathrm{MPa})$ & Normalized (to mix N00) & Normalized (to mixes: R350/R700/R1000) \\
\hline \multirow{4}{*}{ Reference group or G0 } & N00 & 5.02 & 1 & - \\
\hline & R350 & 4.65 & 0.93 & 1 \\
\hline & R700 & 4.25 & 0.85 & 1 \\
\hline & $\mathrm{R} 1000$ & 4.08 & 0.81 & 1 \\
\hline \multirow{5}{*}{ G1 } & R354 & 4.84 & 0.96 & 1.04 \\
\hline & R358 & 4.89 & 0.97 & 1.05 \\
\hline & R3512 & 4.94 & 0.98 & 1.06 \\
\hline & $\mathrm{R} 3516$ & 5.07 & 1.01 & 1.09 \\
\hline & $\mathrm{R} 3520$ & 5.39 & 1.07 & 1.16 \\
\hline \multirow{5}{*}{ G2 } & R704 & 4.28 & 0.85 & 1.01 \\
\hline & R708 & 4.36 & 0.87 & 1.03 \\
\hline & R7012 & 4.63 & 0.92 & 1.09 \\
\hline & R7016 & 4.77 & 0.95 & 1.12 \\
\hline & R7020 & 4.87 & 0.97 & 1.15 \\
\hline \multirow{5}{*}{ G3 } & R1004 & 4.03 & 0.80 & 0.99 \\
\hline & R1008 & 4.54 & 0.90 & 1.11 \\
\hline & R10012 & 4.86 & 0.97 & 1.19 \\
\hline & R10016 & 4.87 & 0.97 & 1.19 \\
\hline & R10020 & 4.98 & 0.99 & 1.22 \\
\hline
\end{tabular}

surface of the RCA particles and pore structure of the cement paste. The high surface area of the MK particles contributes to fill up the microcracks on the RCA leading to a strong RCA. The pozzolanic reaction helps in refining the pore structure of the paste and the ITZ by consuming the $\mathrm{Ca}(\mathrm{OH})$ existing on the surface of the concrete and forming more $\mathrm{C}-\mathrm{S}-\mathrm{H}$ gel which improves the modulus of elasticity (stiffness) of the concrete $[20,24]$.

3.6. Empirical Formulas among Mechanical Properties. In this part, the obtained results of the mechanical properties including compressive strength, splitting tensile strength, flexural strength, and modulus of elasticity were used to develop empirical equations among these properties. Moreover, the developed empirical equations were compared with the standard equation available in the codes of practice such as ACI 31802 (American Concrete Institute) [37], BS 8500 [38] (British standards), and EU-code EN-2004 (Euro code) [39]. The aim is to assess the suitability of using the current equations introduced by available codes of practice to estimate the mechanical properties of recycled aggregate concrete containing MK.

3.6.1. Splitting Tensile Strength vs. Compressive Strength. Figure 16 shows the relations between the compressive strength and splitting tensile strength of all mixes made with RCA. The experimental data from the compression and tensile tests were used to develop the relation between these two mechanical properties. Using linear regression analysis, 


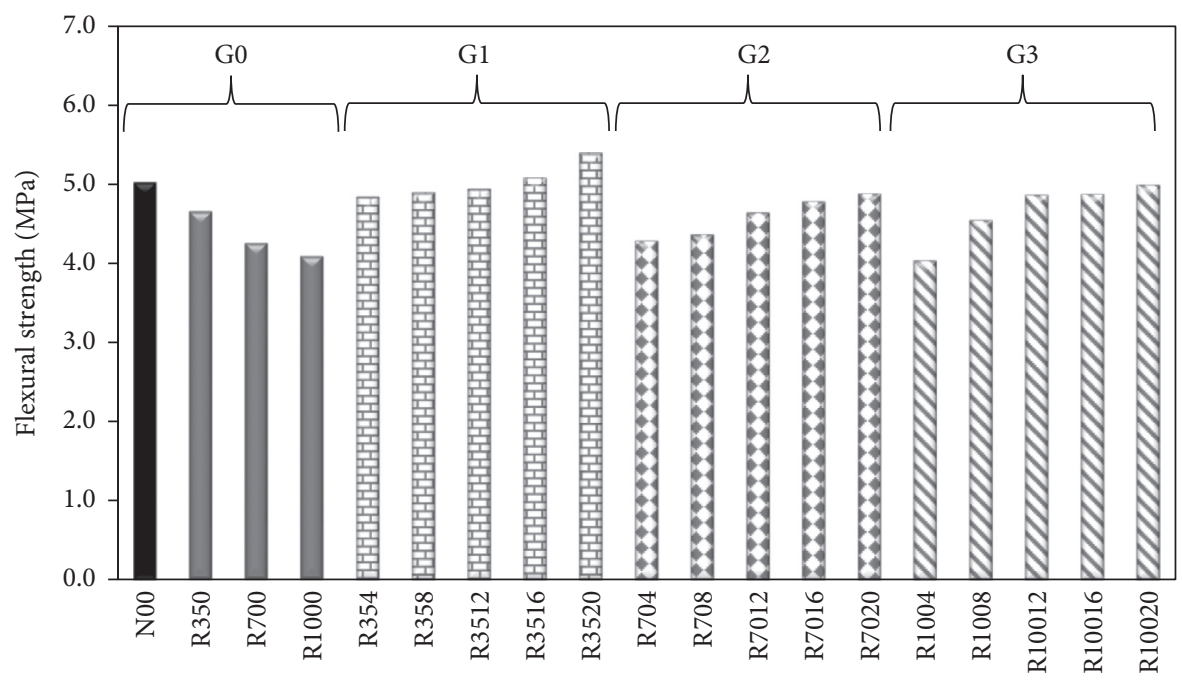

Type of concrete mix

FIgURE 14: Flexural strength after 28 days of curing.

TABLe 7: Modulus of elasticity (results and normalized values).

\begin{tabular}{|c|c|c|c|c|}
\hline \multirow{2}{*}{ Group } & \multirow{2}{*}{ Mix designation } & \multicolumn{3}{|c|}{ Modulus of elasticity } \\
\hline & & Value (GPa) & Normalized (to mix N00) & Normalized (to mixes: R350/R700/R1000) \\
\hline \multirow{4}{*}{ Reference group or G0 } & N00 & 37.4 & 1 & - \\
\hline & R350 & 32.1 & 0.86 & 1.0 \\
\hline & $\mathrm{R} 700$ & 31.0 & 0.83 & 1.0 \\
\hline & R1000 & 30.1 & 0.80 & 1.0 \\
\hline \multirow{5}{*}{ G1 } & R354 & 33.9 & 0.91 & 1.06 \\
\hline & $\mathrm{R} 358$ & 34.1 & 0.91 & 1.06 \\
\hline & $\mathrm{R} 3512$ & 35.0 & 0.94 & 1.09 \\
\hline & $\mathrm{R} 3516$ & 35.7 & 0.95 & 1.11 \\
\hline & $\mathrm{R} 3520$ & 36.8 & 0.98 & 1.15 \\
\hline \multirow{5}{*}{ G2 } & R704 & 33.6 & 0.90 & 1.08 \\
\hline & R708 & 33.7 & 0.90 & 1.09 \\
\hline & R7012 & 34.4 & 0.92 & 1.11 \\
\hline & R7016 & 35.3 & 0.94 & 1.14 \\
\hline & R7020 & 36.0 & 0.96 & 1.16 \\
\hline \multirow{5}{*}{ G3 } & R1004 & 31.1 & 0.83 & 1.03 \\
\hline & R1008 & 31.6 & 0.84 & 1.05 \\
\hline & R10012 & 32.7 & 0.87 & 1.09 \\
\hline & R10016 & 33.2 & 0.89 & 1.10 \\
\hline & R10020 & 33.3 & 0.89 & 1.11 \\
\hline
\end{tabular}

a regression equation can be developed from this figure. It can be seen that there is a correlation coefficient $\left(R^{2}\right)$ of 0.55 between the compressive strength and the splitting tensile strength of the mixes made with RCA. The equation can be expressed as follows (from Figure 16):

$$
f_{s p}=0.8\left(f_{c}\right)^{0.4}
$$

where $f_{s p}$ is the splitting tensile strength and $f_{c}$ is the compressive strength of the concrete.

3.6.2. Flexural Strength vs. Compressive Strength. The experimental results of the flexural and compression tests of all mixtures containing RCA are plotted and shown in
Figure 17. It can be seen that there is a correlation between the two properties, and the correlation coefficient $\left(R^{2}\right)$ is equal to 0.71 . It was found that the best equation that best fits all the results is a power equation as can be seen in Figure 17. The equation that represents this relation can be expressed as follows:

$$
f_{r}=0.49\left(f_{c}\right)^{0.61}
$$

where $f_{\mathrm{r}}$ is the splitting tensile strength and $f_{c}$ is the compressive strength of the concrete.

3.6.3. Elastic Modulus vs. Compressive Strength. Figure 18 depicts the experimental data from the compression and modulus of elasticity $(\mathrm{Ec})$ tests of all mixes made with RCA. 


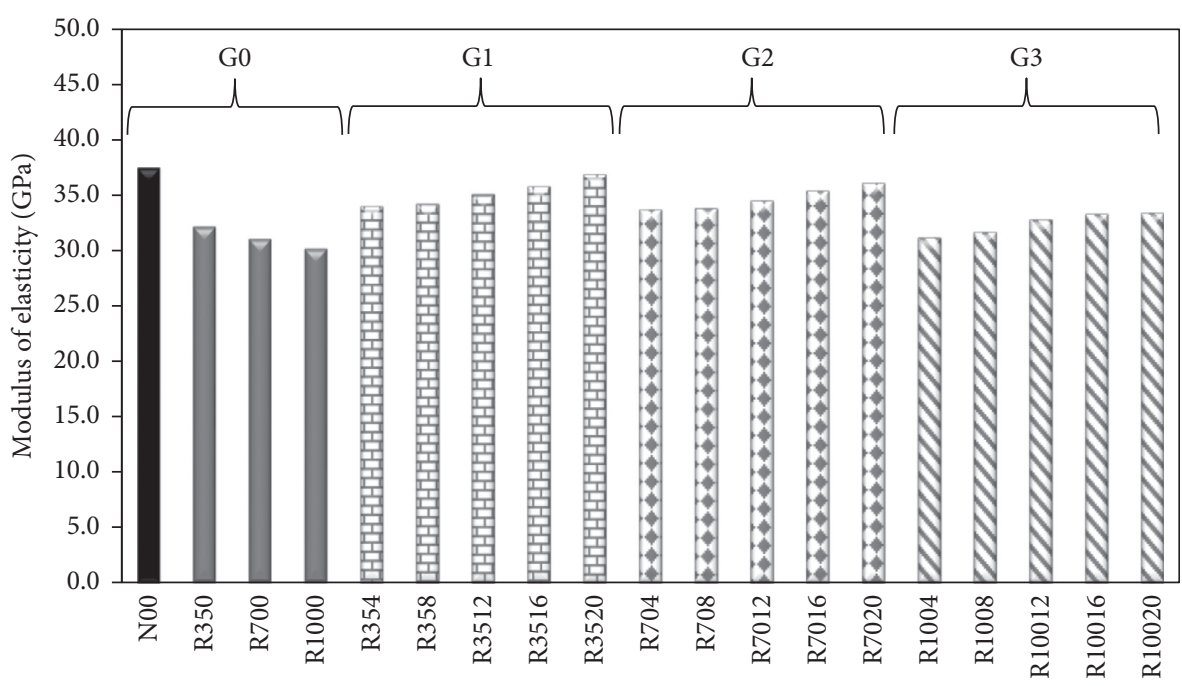

Type of concrete mix

FIgURE 15: Modulus of elasticity after 28 days of curing.

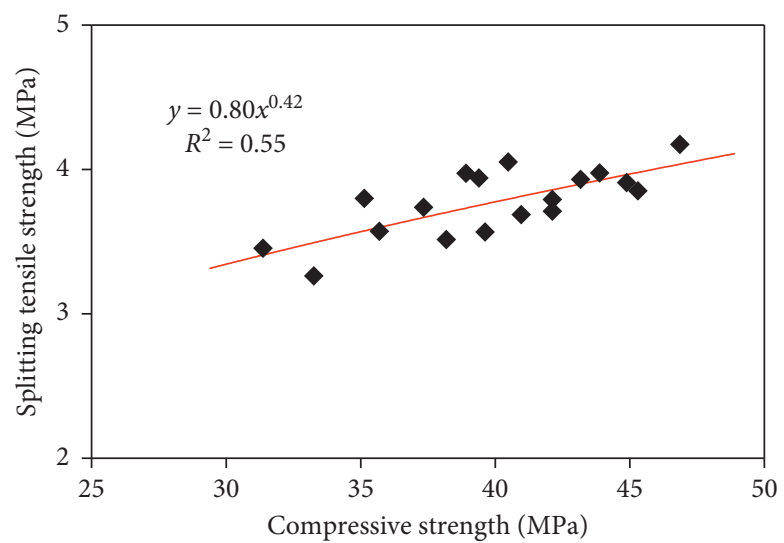

FIgURE 16: Correlation between splitting tensile strength and compressive strength of the mixes with RCA.

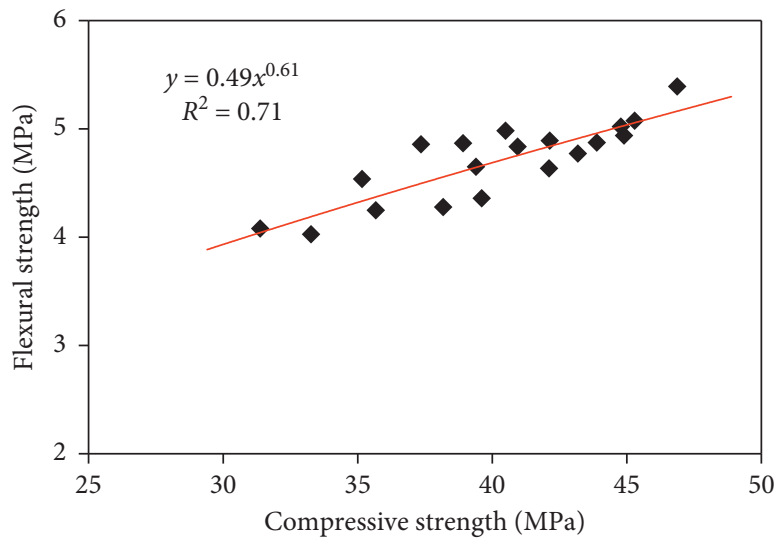

FIgURE 17: Correlation between flexural strength and compressive strength of the mixes with RCA.

These results were used to develop the relation between these two mechanical properties. From this figure and by using linear regression analysis, a regression equation can be developed. The figure shows that there is a strong correlation between the compressive strength ( $\mathrm{fc}$ in $\mathrm{MPa}$ ) and the elastic modulus (Ec in GPa) of all concretes made with RCA. The strong relationship is supported by the very high correlation coefficient $R^{2}$ which is equal to 0.92 as can be seen in 


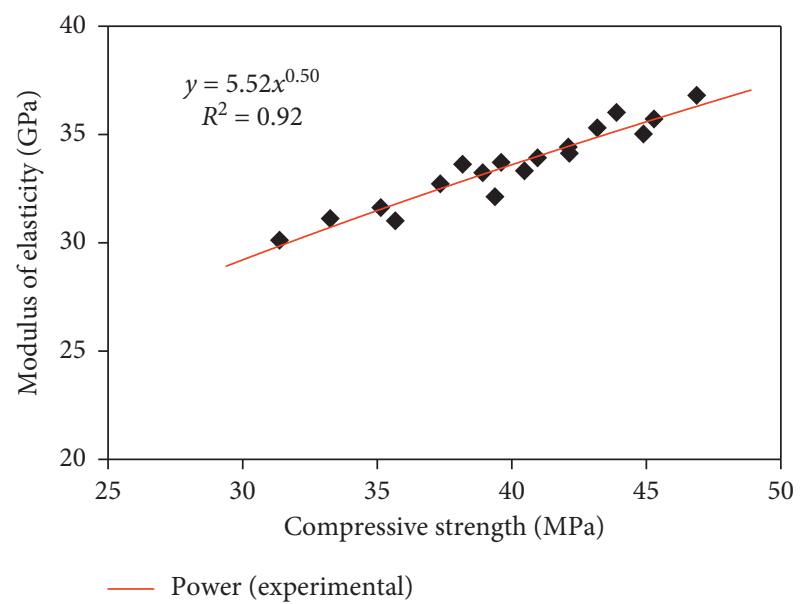

FIGURE 18: Correlation between modulus of elasticity and compressive strength of the mixes with RCA.

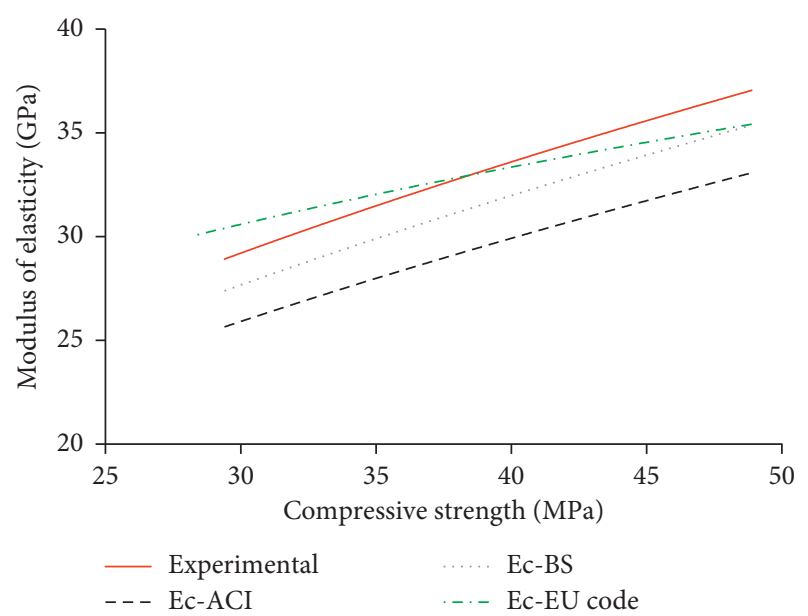

Figure 19: Comparing the developed empirical equation of $E_{\mathrm{c}}$ with the standard codes of practice.

Figure 18. The developed equation is a power equation and can be expressed as follows:

$$
E_{c}=5.52 \sqrt{f_{c}} .
$$

From equation (3) $(E c=5.52 \sqrt{ } f \mathcal{c})$, the elastic modulus of the RCA concrete mixes with or without MK can be predicted using its compressive strength. To assess the validity of this model, we should compare it with other models from international codes of practice. The ACI 318-02 model for predicting $E_{c}$ for natural aggregate concrete is $E_{c}=4.7 \sqrt{ } f_{c}$. The BS 8110 proposes the model $E_{c}=5 \sqrt{ } f_{c}$ to estimate $E_{c}$ for normal concrete. The Euro code EN-2004 uses the model $E_{c}=22\left(f_{c k} / 10\right)^{0.3}$. The results of the experiments of this study were used to predict the $E c$ value of each mix using the models proposed by these codes of practice. The results of predicted Ec are depicted in Figure 19. For comparison reasons, the results of the empirical model to estimate Ec developed in this study are also plotted in Figure 19. It can be seen that the estimated Ec using the developed model is higher than that of the BS and the ACI models. This means that these models underestimate Ec of the mixes with RCA (with and without MK). This could be due to the fact that this model includes both mixes of RCA, modified with MK and those have no MK. The mechanical properties of the mixes with RCA were improved using MK meaning higher strength than mixes without $\mathrm{MK}$ and even higher than the reference mix N00 in some cases which could be the reason that led the developed model to appear above the models of these codes. However, the developed model is more comparable to the model of Eurocode 2 as can be seen in Figure 19. This model slightly overestimates Ec of the current study up to $\mathrm{fc}_{\mathrm{c}}$ in the range of $38-42 \mathrm{MPa}$ and slightly underestimates the Ec value after this range of strength. Hence, the Eurocode can better estimate Ec of the RAC mixes made with or without MK.

\section{Conclusions}

In the current research, mechanical performance of RAC including various contents of RCA and incorporating different dosages of $\mathrm{MK}$, as cement replacement, is examined. The following conclusions are highlighted based on the outcomes of current work.

(i) Replacing NCA with RCA reduces the workability of concrete. This reduction increases with the increase of RCA content. When $100 \%$ of the NCA was replaced with RCA, the concrete loses about $36 \%$ of its slump value. This can be due to the rough surface of the RCA and the high absorption capacity of the RCA particles.

(ii) The use of MK as partial replacement of the OPC decreases the workability of RAC. The decrease in workability is attributed to the percentage of MK. A decrease of up to $52 \%$ was observed for the mix made with $100 \%$ RAC and $20 \% \mathrm{MK}$. This is due to the high surface area of the MK particles and because of the agglomeration and electrostatic attraction that hinder the movement of the matrix, hence decreasing workability.

(iii) The utilization of RCA at contents of 35\%, 70\%, and $100 \%$ decreases the compressive strength of the NAC by $12 \%, 20 \%$, and $30 \%$, reduces the splitting tensile strength by $2 \%, 11 \%$, and $14 \%$, reduces the flexural strength by $7 \%, 155$, and $19 \%$, and reduces the modulus of elasticity by $14 \%, 17 \%$, and $19 \%$, respectively. This is because of the low quality of the RCA resulting from the attached mortar and the weak and porous ITZ.

(iv) The partial replacement of OPC with MK at contents $4 \%, 8 \%, 12 \%, 16 \%$, and $20 \%$ can improve the compressive strength of RAC. At $20 \%$ of MK, the compressive strength increases to reach a value that is comparable to that of the NAC mix and higher than that of RAC without MK by $19 \%, 23 \%$, and $29 \%$. This strength enhancement is due to 
physical/chemical mechanisms. The former is achieved by the filling ability of the very fine particles of the MK, whereas the latter is developed by the pozzolanic reaction of the MK which contributes to densifying the ITZ of the RAC.

(v) The influence of MK on the strength of the RCA mixes is more influential at early ages than later ages. Mixes including MK exhibit higher rate of strength development than those without MK particularly after the age of 28 days and up to 90 days.

(vi) Just as the trend of the compressive strength, the splitting tensile strength, flexural strength, and modulus of elasticity (at all contents of RCA) increase as the content of $\mathrm{MK}$ increases. For the RAC mix made with $100 \%$ RCA and $20 \%$ of MK, splitting tensile strength, flexural strength, and modulus of elasticity increased by $17 \%, 22 \%$, and $11 \%$ compared to the RAC mix without MK.

(vii) Empirical equations (models) among the mechanical properties of the RAC mixes made with MK were developed. These equations show correlations between compressive strength and other mechanical properties as $R^{2}$ was 0.55 (for the splitting tensile strength), 0.71 (for the flexural strength), and 0.92 (for the elastic modulus).

(viii) The developed empirical model of the elastic modulus is more comparable to the model developed by Eurocode 2 (EN-2004) standard, whereas the models of the ACI 318-02 and BS 8110-1 underestimate the results of the elastic modulus in comparison with the developed model in this study.

\section{Data Availability}

The data used to support the findings of this study are included within the article.

\section{Conflicts of Interest}

The authors declare that they have no conflicts of interest.

\section{Acknowledgments}

The authors acknowledge the support and help provided by Erbil Polytechnic University and Tishk International University.

\section{References}

[1] P. K. Mehta and P. J. M. Monteiro, Concrete: Microstructure, Properties, and Materials, McGraw-Hill, New York, USA, 2006.

[2] K. H. Younis, "Restrained shrinkage behaviour of concrete with recycled materials," $\mathrm{Ph}$. D Thesis in Civil and Structural Engineering, University of Sheffield, Sheffield, UK, 2014, http://etheses.whiterose.ac.uk/id/eprint/5966.
[3] V. W. Y. Tam and C. M. Tam, Re-use of Construction and Demolition Waste in Housing Developments, Nova Science Publishers, New York, USA, 2008.

[4] K. H. Younis and K. Pilakoutas, "Strength prediction model and methods for improving recycled aggregate concrete," Construction and Building Materials, vol. 49, pp. 688-701, 2013.

[5] W. Chen, R. Jin, Y. Xu et al., "Adopting recycled aggregates as sustainable construction materials: a review of the scientific literature," Construction and Building Materials, vol. 218, pp. 483-496, 2019.

[6] N. Kisku, H. Joshi, M. Ansari, S. K. Panda, S. Nayak, and S. C. Dutta, "A critical review and assessment for usage of recycled aggregate as sustainable construction material," Construction and Building Materials, vol. 131, pp. 721-740, 2017.

[7] T. Xie, A. Gholampour, and T. Ozbakkaloglu, "Toward the development of sustainable concretes with recycled concrete aggregates: comprehensive review of studies on mechanical properties," Journal of Materials in Civil Engineering, vol. 30, no. 9.

[8] K. H. Younis and S. M. Mustafa, "Feasibility of using nanoparticles of $\mathrm{SiO} 2$ to improve the performance of recycled aggregate concrete," Advances in Materials Science and Engineering, vol. 2018, Article ID 1512830, 11 pages, 2018.

[9] V. W. Y. Tam, C. M. Tam, and K. N. Le, "Removal of cement mortar remains from recycled aggregate using pre-soaking approaches," Resources, Conservation and Recycling, vol. 50, no. 1, pp. 82-101, 2007.

[10] V. W. Y. Tam, K. Wang, and C. M. Tam, “Assessing relationships among properties of demolished concrete, recycled aggregate and recycled aggregate concrete using regression analysis," Journal of Hazardous Materials, vol. 152, no. 2, pp. 703-714, 2008.

[11] M. Gomes and J. de Brito, "Structural concrete with incorporation of coarse recycled concrete and ceramic aggregates: durability performance," Materials and Structures, vol. 42, no. 5, pp. 663-675, 2009.

[12] V. W. Y. Tam and C. M. Tam, "Parameters for assessing recycled aggregate and their correlation," Waste Management and Research, vol. 27, no. 1, pp. 52-58, 2009.

[13] A. Katz, "Treatments for the improvement of recycled aggregate," Journal of Materials in Civil Engineering, vol. 16, no. 6, pp. 597-603, 2004.

[14] V. W. Y. Tam and C. M. Tam, "Diversifying two-stage mixing approach (TSMA) for recycled aggregate concrete: TSMAs and TSMAsc," Construction and Building Materials, vol. 22, no. 10, pp. 2068-2077, 2008.

[15] H. Y. Khaleel and M. M. Shelan, "Application of nano materials to enhance mechanical performance and microstructure of recycled aggregate concrete," in Proceedings of the 4th International Engineering Conference on Developments in Civil and Computer Applications IEC2018, Erbil Ploytechnic University and Ishik University: Erbil-Iraq, February 2018.

[16] K. H. Younis, F. F. Jirjis, G. J. Khoshnaw, and H. Brham, "Experimental study on performance of recycled Aggregate Concrete: effect of reactive microfillers," International Journal of Civil Engineering and Technology, vol. 10, no. 1, pp. 2566-2576, 2019.

[17] S. C. Kou, C. S. Poon, and D. Chan, "Influence of fly ash as a cement addition on the hardened properties of recycled aggregate concrete," Materials and Structures, vol. 41, no. 7, pp. 1191-1201, 2008. 
[18] S.-C. Kou, C.-S. Poon, and F. Agrela, "Comparisons of natural and recycled aggregate concretes prepared with the addition of different mineral admixtures," Cement and Concrete Composites, vol. 33, no. 8, pp. 788-795, 2011.

[19] M. L. Berndt, "Properties of sustainable concrete containing fly ash, slag and recycled concrete aggregate," Construction and Building Materials, vol. 23, no. 7, pp. 2606-2613, 2009.

[20] R. Siddique and J. Klaus, "Influence of metakaolin on the properties of mortar and concrete: a review," Applied Clay Science, vol. 43, no. 3-4, pp. 392-400, 2009.

[21] P. Duan, Z. Shui, W. Chen, and C. Shen, "Effects of metakaolin, silica fume and slag on pore structure, interfacial transition zone and compressive strength of concrete," Construction and Building Materials, vol. 44, pp. 1-6, 2013.

[22] M. Antoni, J. Rossen, F. Martirena, and K. Scrivener, "Cement substitution by a combination of metakaolin and limestone," Cement and Concrete Research, vol. 42, no. 12, pp. 1579-1589, 2012.

[23] E. Guneyisi, M. Gesoglu, S. Karaoğlu, and K. Mermerdaş, "Strength, permeability and shrinkage cracking of silica fume and metakaolin concretes," Construction and Building Materials, vol. 34, no. 0, pp. 120-130, 2012.

[24] R. Muduli and B. B. Mukharjee, "Effect of incorporation of metakaolin and recycled coarse aggregate on properties of concrete," Journal of Cleaner Production, vol. 209, pp. 398414, 2019.

[25] K. Kapoor, S. P. Singh, and B. Singh, "Permeability of selfcompacting concrete made with recycled concrete aggregates and metakaolin," Journal of Sustainable Cement-Based Materials, vol. 6, no. 5, pp. 293-313, 2018.

[26] N. Singh and S. P. Singh, "Carbonation and electrical resistance of self compacting concrete made with recycled concrete aggregates and metakaolin," Construction and Building Materials, vol. 121, pp. 400-409, 2016.

[27] BS EN 12350-2, Testing Fresh Concrete - Part 2: Slump Test, British Standards Institution, London, UK, 2009.

[28] BS EN 12390-3:2009, Testing Hardened Concrete Part 3: Compressive Strength of Test Specimens, British Standards Institution, London, UK, 2009.

[29] BS. EN. 12390:6-2009, Testing Hardened Concrete Part 6: Splitting Tensile Strength of Test Specimens, British Standard Institution, London, UK, 2009.

[30] BS EN 12390-5:2009, Testing Hardened Concrete Part 5: Flexural Strength of Test Specimens, British Standards Institution, London, UK, 2009.

[31] ASTM C642-13, Standard Test Method for Density, Absorption, and Voids in Hardened Concrete. 2103, American Standards for Testing and Materials, ASTM ASTM International, West Conshohocken, PA, USA, 2013.

[32] J. Li, H. Xiao, and Y. Zhou, "Influence of coating recycled aggregate surface with pozzolanic powder on properties of recycled aggregate concrete," Construction and Building Materials, vol. 23, no. 3, pp. 1287-1291, 2009.

[33] M. Nehdi, S. Mindess, and P.-C. Aritcin, "Rheology of highperformance concrete: effect of ultrafine particles," Cement and Concrete Research, vol. 28, no. 5, pp. 687-697, 1998.

[34] W. Li, C. Long, V. W. Y. Tam, C.-S. Poon, and W. Hui Duan, "Effects of nano-particles on failure process and microstructural properties of recycled aggregate concrete," Construction and Building Materials, vol. 142, no. Supplement C, pp. 42-50, 2017.

[35] V. W. Y. Tam, X. F. Gao, and C. M. Tam, "Microstructural analysis of recycled aggregate concrete produced from two- stage mixing approach," Cement and Concrete Research, vol. 35, no. 6, pp. 1195-1203, 2005.

[36] H. Moosberg-Bustnes, B. Lagerblad, and E. Forssberg, "The function of fillers in concrete," Materials and Structures, vol. 37, no. 2, pp. 74-81, 2004.

[37] ACI 231r-10, Report On Early-Age Cracking: Causes, Measurement, And Mitigation, In ACI Committee 231, American Concrete Institute, Farmington Hills, U.S.A, 2010.

[38] BS 8500-2, Concrete Complementary British Standard to BS EN 206 Part 1 -Part 2: Specification for Constituent Materials and Concrete, British Standard Institiution, London, UK, 2006.

[39] BS EN 1992-1-1:2004, Eurocode 2: Design of Concrete Structures - Part 1-1: General Rules and Rules for Buildings, British Standard Institution, London, UK, 2004. 